Estudios Románicos, Volumen 29, 2020, pp. 79-91

ISSN: 0210-4911

eISSN: 1989-614X

DOI: https://doi.org/10.6018/ER.417271

\title{
LA TÉCNICA EPISTOLAR EN LA TERCERA SERIE DE LOS EPISODIOS NACIONALES
}

(The epistolary technique in the third series of the National Episodes)

\author{
Ana L. Baquero Escudero* \\ Universidad de Murcia
}

\begin{abstract}
In the narrative configuration of the Third Series of the National Episodes the inclusion of letter is striking. Galdós includes here an epistolary novel as well as two partially epistoray novels and he intercalates several letters in the remaining works. The present work deals, then, with the Galdosian handling of the epistolary technique in this set of novels that reveals, also, the versatility and the literary genius of the Canarian author.
\end{abstract}

Keywords: Galdós; National Episodes; Third Series; Epistolary technique; Epistolary Novel.

Resumen: En la configuración narrativa de la tercera serie de los Episodios nacionales resulta especialmente llamativa la inclusión de cartas. Galdós incluye aquí tanto una novela epistolar, como dos parcialmente epistolares e intercala numerosas cartas en las restantes obras. El presente trabajo aborda, pues, el manejo galdosiano de la técnica epistolar en este conjunto novelesco que revela, también, la versatilidad y el genio literario del autor canario.

Palabras clave: Galdós; Episodios nacionales; Tercera serie; Técnica epistolar; Novela epistolar.

Los hechos históricos recogidos en esta serie cubren el convulso período entre 1833 y 1846, en el que el Romanticismo había ido adueñándose de la esfera literaria. Junto a ambos aspectos, fundamentales en su construcción, Galdós desplegará su personal ficción novelesca que, a diferencia de las series anteriores, no constituye una única

* Dirección para correspondencia: Dpto. Literatura Española, Teoría de la Literatura y Literatura Comparada. Facultad de Letras. 30001. Universidad Murcia. abaquero@um.es. Estudio realizado en el marco del GREGAL y del proyecto GENUS NOVEL 2017-82662-P. 
trama protagonizada por dos personajes centrales. Estrechamente conectadas ocho de las obras, tanto la inicial como la última evidencian el cambio del método utilizado. Habrá que esperar, así, a la segunda para encontrarnos con Fernando Calpena, quien desaparece en la última y es claramente desplazado por otros personajes en La campaña del Maestrazgo y Montes de Oca. La alternancia, pues, de lo que podría estimarse historia central, con otras protagonizadas por diversos personajes -Fago, don Beltrán, Ibero, la familia de don Bruno- complica la construcción de la trama novelesca que aparece escindida en direcciones varias. Y junto a ello también se advierte una mayor riqueza en la elaboración del propio discurso novelesco. Como bien ha precisado Penas (2013: 31), puede hablarse de una compleja construcción del discurso de esta serie a lo que contribuye, sin duda, el manejo del recurso epistolar. Si en algunos de los episodios de la serie anterior Galdós había cambiado de sujeto enunciativo, pasando de la tercera a la primera persona, ahora el cambio será múltiple pues van a ser muchos los personajes que intercambien cartas ${ }^{1}$. La estafeta romántica resulta, así, una novela epistolar polifónica en la que, señala Guadalupe Mella (2016), confluyen cartas-drama, con cartas-confidencia, según la tipología de Jost (1968). Situada en la parte central del conjunto, el recurso epistolar de innegable relieve en el desarrollo de las novelas anteriores, se convierte ahora en el formato único, generador del discurso narrativo. Como en La incógnita, tampoco hallamos aquí, frente a los modelos dieciochescos, el manejo de la estrategia del editor responsable de publicar la correspondencia ${ }^{2}$. Que Galdós se distancia de la forma anterior dominante en el género se percibe con claridad en la novela siguiente, Vergara, continuación o epígono de ella, como indica Penas (2013: 135). Aquí la súbita interrupción y continuación de la historia se resuelve con el irónico comentario: "Agotada la preciosa colección de cartas que un Hado feliz puso en manos del narrador [...]" (2016b: 255) $)^{3}$.

Como ha señalado Bernal (1985), de todas las novelas esta resulta la más intrahistórica, constituyéndose como uno de sus ejes centrales, la literatura romántica (Díez de Revenga 1989, Penas 2013: 126-134). Construida la correspondencia epistolar sobre los intercambios de un elevado número de personajes, el lector ya conocía la escritura epistolar de muchos de ellos, pues en las novelas anteriores la incorporación de cartas se constituyó en práctica habitual. Tras ella, Galdós configurará parcialmente la séptima y la novena, en formato epistolar. En consecuencia, resultaría inconcebible una tercera serie expurgada de cartas, al erigirse estas en un elemento fundamental en la estructura narrativa del conjunto. Pese a que resulta imposible un detenido análisis de todas ellas, abordaremos algunos aspectos fundamentales en el uso de la escritura epistolar, para ver cómo son manejados por Galdós.

$1 \quad$ Sobre el manejo y función de las cartas en estas novelas, Penas (2013: 31-32).

2 Sobre la búsqueda, en la novela epistolar dieciochesca, de provocar la ilusión de no ficcionalidad, Calas (1996:110) y Tonyè (2008: 46). Sobre la distinta posición de los escritores decimonónicos, Guadalupe Mella (2016: 47). Sobre la escritura epistolar en la centuria dieciochesca, Cantos Casenave (2015).

3 Un esquema similar se reproduce en Los Ayacuchos, Cap. XXX, construida en buena parte sobre el artificio epistolar. 


\section{Flexibilidad y variedad temática}

Sin duda uno de los rasgos inherentes de lo que podemos estimar como carta privada es su amplitud de registros, capaz de albergar una gran variedad temática. Tal principio fue ya recogido en la tradición de los manuales epistolográficos los cuales, como recoge Pagés-Rangel (1997:11-13), evidencian la casi ilimitada capacidad de la carta para admitir todo tipo de estilos y temas. De ello se aprovecha la ficción literaria, al incorporar la escritura epistolar dentro de sus propios cauces. No resulta, así, extraño que Montesquieu blandiera, en sus Cartas persas (1997: 57), como una de las grandes ventajas del método epistolar, la posibilidad de mezclar temas de los más diversos ámbitos. De forma que si conforme al modelo canónico del género, dicha dispersión temática podría resultar digresiva, no lo es dentro de la forma que él ha elegido. A la consustancial flexibilidad e hibridismo propios de la novela se une, pues, en el caso de la epistolar, el exclusivo manejo de una forma textual -la carta- caracterizada por tal principio. En el caso de la tercera serie, Galdós utilizará tanto la novela epistolar como el manejo reiterado de cartas en el modelo dominante entonces de la novela impersonal, lo que da lugar, en ambos casos, a un variado y rico mosaico temático. Transcritas total o parcialmente, o referidas, las cartas ocupan un destacado lugar y, conforme a las exigencias de la trama novelesca, ofrecen un amplio perfil tipológico.

Quizá la correspondencia cuya inclusión desempeñe una función más relevante se concentre en la de Fernando y su madre. En este caso las cartas iniciales de la mano oculta responden a una intencionalidad que podríamos considerar pedagógica, al intentar encauzar y controlar la vida del joven, en principio, y después también la de quien considera su guía, D. Pedro Hillo. La situación creada aquí por Galdós presenta innegables ecos literarios pues la aparición de un hijo ilegítimo, que resulta ser hijo de una dama noble, evoca tanto las tradicionales anagnórisis, como un motivo tópico de la literatura folletinesca. Cercano a él no puede ser olvidado el nombre de Dickens y sus Grandes esperanzas. En la misteriosa relación entre protector y protegido Galdós opta, sin embargo, por una estrategia distinta pues, frente al novelista inglés, él acude a un intercambio epistolar que va marcando y desarrollando la compleja relación entre los corrresponsales. Si esas cartas dirigidas a Fernando responden a esa mencionada intención educadora, en las que escribe a Valbanera se aprecia un matiz bien distinto. Como ha estudiado Behiels (2001), en ellas cambia completamente el tono usado por el personaje, dando lugar a un implacable autoanálisis psicológico. Ahora estamos ante cartas entre dos amigas ${ }^{4}$. Precisamente en La estafeta encontramos otro de los topos de la comunicación epistolar: la carta como reflejo de quien escribe. Valbanera insta, así, a su amiga a que no limite sus cartas "porque en tu escritura y estilo te veo tan viva como si delante te tuviera. No hay persona que tan claramente se muestre en lo que escribe" (2016b: 107). La asociación aquí con un modelo literario nos llevaría a otro de los grandes maestros de Galdós, pues las Memorias de dos recién casadas de Balzac está

4 Ana Rueda ha incidido en la importancia, en la novela epistolar, de la relación amistosa (2001: 202290). 
construida sobre la relación epistolar entre dos amigas (Paradissis 1978). Por lo demás, parece que Galdós confiere un especial relieve a este tipo de correspondencia epistolar femenina, pues junto a la establecida entre Pilar y Valbanera se presenta la mantenida entre Juana Teresa y $\mathrm{M}^{\mathrm{a}}$. Tirgo. Sin olvidar los cruces entre ambos grupos que, como recoge Penas (2013:119), fueron objeto del elogio clariniano.

El caso de Pilar de Loaysa es el de un personaje cuyo carácter se construye, de forma casi total, a partir de su escritura epistolar pues sus principales marcas caracterizadoras proceden de sus cartas. En estas cabría percibir esas dos modalidades destacadas por Jost (1968). Por una parte, su correspondencia inicial con Fernando implica un avance de la historia, con las consecuencias que ello conlleva en las oscilaciones del héroe ante ella. Frente a estas lettres-drames las que envía a Valbanera caerían en el ámbito de las lettres-confidences aunque, conforme a la natural flexibilidad del género epistolar, unas $\mathrm{y}$ otras puedan rebasar tales limitaciones.

El carácter naturalmente misceláneo de la epístola permite, asimismo, la transición de temas, por lo que no será infrecuente que esa cuidadosa mixtura ficción-historia, adquiera notorio perfil en muchas de estas cartas. La mezcla de temas de índole privada y doméstica con el relato de hechos históricos será habitual en muchas de ellas. Especialmente representativas pueden resultar, en tal sentido, las que la incógnita escriba a Fernando e Hillo, encerrados en prisión. Si el personaje, indudablemente, se refiere a hechos ligados a la trama novelesca, el escritor aprovecha su situación extramuros para pasar revista tanto a la situación política como literaria. En esas cartas insertas en De Oñate a La Granja la autora asombra a sus destinatarios por sus agudas apreciaciones sobre la situación política, a la par que comenta el estreno de El trovador o pasa revista a la prensa. En algunas cartas los personajes se centran, no obstante, en el relato de sucesos históricos que quedan tamizados a través del personal filtro de una subjetividad. Recuérdese, tan solo, el inicio de Luchana en donde Pilar relata a su hijo la sublevación de La Granja o las noticias que a través de sus cartas ofrece el itinerante D. Beltrán, en La estafeta. El manejo de la técnica epistolar vinculado al relato de hechos históricos adquiere un singular relieve en Los Ayacuchos, en donde el escritor aprovecha la naturaleza perspectivista de la misma para ofrecer un mismo suceso a través de enfoques contrapuestos. Muy distinta es, así, la relación que hacen a Fernando, Centurión y Socobio sobre el fallido rapto de Isabel y su hermana.

Constituyéndose como uno de los ejes temáticos que atraviesa la ficción novelesca la relación amorosa, este no podía faltar en la correspondencia epistolar. En Mendizábal hallamos una situación de antiquísima tradición literaria, centrada en la relación amorosa obstaculizada que solo puede ser mantenida a través del intercambio epistolar. Férreamente contraria a los amores de Aura y Fernando, Jacoba somete a escrupuloso registro a Lopresti, mensajero de los enamorados, "guardando bajo llave papeles, pluma y tinta: por su gusto habría borrado de las costumbres humanas [...] el arte de la escritura" (2016a: 468) Ante tales obstáculos los personajes recurrirán al ingenio para llevar sus mensajes escondidos en el sombrero de Milagro quien se convierte "en conductor inocente de la amorosa correspondencia" (2016a: 469) Esta, como precisa el narrador, era auténtico "fuego, llamas cogidas a puñados del mismo sol" (2016a: 
469) y de ella ofrece una significativa muestra. Frente a esa breve pero representativa selección de tal correspondencia, distinta es la situación que encontramos en $L a$ campaña del Maestrazgo. Nuevamente la carta aparece en esta obra al servicio de la seducción amorosa, pues a ella acudirá Nelet para llegar a Marcela. Ninguna de las cartas se reproduce, sin embargo, pese a que hay variadas referencias a la insistencia de la comunicación escrita entre ambos. También en Bodas reales Terry se valdrá del asedio epistolar, pues, como indica el narrador, este envía "las cartitas que acabaron de soliviantar a la desdichada Eufrasia" (2016b: 1040) Unas cartas que tampoco son reproducidas. En general, y no deja de resultar significativo en una serie en la que la inclusión de cartas es tan ostensible, las de tipo amoroso suelen omitirse. Recuérdese la también mera mención del carteo entre Ibero y Gracia en Montes de Oca.

Si Galdós se mueve dentro de una larga tradición literaria al incluir en su ficción novelesca las convenciones vinculadas al intercambio epistolar amoroso, en algún caso alguno de sus personajes parece, incluso, admitirlo. En Los Ayacuchos y ante las preguntas de Valvanera, Demetria reconoce su error por la frialdad de su segunda carta a Fernando, consecuencia "del falso amor que hemos aprendido en los libros. Se me puso entre ceja y ceja que debía emplear el jueguecito del desdén con el desdén" (2016b: 692). Efectivamente, ya Ovidio prevenía al enamorado del falso rechazo de la amada, en su Arte de amar (1989: 373), y toda una amplia tradición literaria se hace eco de ello.

Por lo demás, en la serie uno de los temas centrales es el ambiente literario, con lo que las referencias a escritores y a las propias aficiones literarias de los personajes recorren sus cartas. Si las costumbres, gustos y relaciones sociales aparecen reflejados en muchas de ellas, la más pura cotidianeidad se abre paso también a través de la escritura epistolar ${ }^{5}$.

Ya se atengan al método activo o pasivo, señalado por Jost, ya sirvan de sustancial apoyo para la trama o para la construcción del carácter del personaje, ya se presenten completas o solo referidas, parece incuestionable que en esta serie la técnica epistolar adquiere notable realce. Galdós explora, así, de manera continuada, las posibilidades novelescas que ofrece ese intercambio entre dos, anejo a esta especie.

\section{La relación epistolar: una comunicación entre dos}

En una comunicación epistolar resultan elementos fundamentales la presencia de un yo que se dirige a un tú. Definida la carta tradicionalmente como un diálogo en la distancia ${ }^{6}$, sin duda tal conformación dialógica resulta necesaria para la configuración del texto epistolar (Violi 1999: 184). En este conjunto de novelas Galdós parte de tal convención para establecer sobre ella un número de combinaciones y variables verdaderamente sorprendente.

En lo que concierne a la figura del emisor puede decirse que la misma se expande por toda una amplísima galería de personajes, que incluye tanto a los ficcionales como

\footnotetext{
5 Recuérdese la incorporación de una receta en una esquela de Demetria (La estafeta, Cap. XVIII).

6 Guillén matizó la proyección de las ideas defendidas por Demetrio, a tal respecto (1998).
} 
a los históricos. A Mendizábal dedica, así, bastante espacio el narrador en su condición de escritor de cartas, incluyéndose también un breve extracto de una redactada por Espartero (Luchana, Cap. XIV). Puede decirse que en esta serie todos los personajes sienten la necesidad, por circunstancias muy diversas, de escribir cartas.

Centrándonos en los galdosianos habría que partir de la dualidad esencial de emisores identificados y sin identificar, pues no siempre las cartas aparecen con la marca identificadora, de la firma. Precisamente es la mera aparición de una firma, en una carta rota, lo que altera visiblemente al protagonista de Zumalacárregi ${ }^{7}$. En lo que respecta al caso de la carta anónima, nuevamente hay que insistir en el relieve de la correspondencia de la mano oculta cuyo anonimato irá progresivamente debilitándose, hasta dar paso a una determinada identidad. Si Hillo estima que podría ser una mujer, a él irá descubriéndose la anónima figura, aunque tarde bastante en concretar su nombre. Este aparece en una carta que recibe Mendizábal, en la novela del mismo título, si bien el lector no puede vincularlo todavía con el corresponsal de Fernando. De hecho, tal como dispone Galdós la conformación de su discurso novelesco, los lectores nos vemos necesariamente sujetos a la percepción de Fernando e Hillo. El narrador, deponiendo su omnisciencia, crea una misteriosa situación, al presentarnos a un personaje que se ve protegido por un anónimo benefactor. Recordemos que Mendizábal, donde por vez primera aparece Fernando, no es una novela epistolar y que el narrador bien podría haber aportado esos datos sustanciales para resolver el enigma. Lejos de ello, sabe que lo necesario, para asegurar la tensión lectora, es atenerse a la presentación de unas cartas sin autor identificado.

Por otra parte, y en relación también con la figura del emisor, cabe hallar la presencia del falso emisor. El joven Calpena entra al servicio de Mendizábal para escribir cartas en su nombre que este después firma (Urey 1985: 463). Aunque quizá el caso más llamativo de carta con falso emisor aparezca en La estafeta, en la que incluye Hillo a Fernando, en una de las suyas, y que, supuestamente, le ha escrito Miguel de los Santos, dándole noticias sobre la muerte de Larra (Sotelo 2015). La superchería epistolar organizada por Pilar pronto se hará visible en la carta que inmediatamente aparece, dirigida a Valbanera. Precisamente tal carta apócrifa evidencia uno de los tópicos más consolidados en la tradición epistolográfica, consistente en la singular naturaleza de la carta como texto paradójicamente conformado entre lo privado y lo público. Como escribe el supuesto Miguel de los Santos, pondrá todo su esfuerzo en la redacción de su texto pues "aunque escribo al parecer para ti solo, en familiar estilo, no puedo tomar la pluma sin pensar que ha de leerme la posteridad" (2016b: 60). La paradójica dualidad privado/público, vinculable al también topos epistolar naturalidad/artificio, no puede hacerse más ostensible en estas líneas ${ }^{8}$.

Otra variante que hallamos en estas novelas consiste en la adopción de una nueva personalidad, proyectada en una firma distinta. De la mantenida relación entre el joven inexperto llegado a la capital y el fiel acompañante que resultará ser su guía surge una estrecha asociación -señalada por la incógnita-, que perfila los papeles de cada

\footnotetext{
7 Recuérdese la impresión que provoca en Agustín Caballero el rabito de la firma de Tormento.

8 Recuérdese su presencia en la novela que dio origen a la eclosión del género en el siglo xvIII, Pamela Andrews (Baquero Escudero, 2003: 88).
} 
uno. No es extraño, así, que Fernando en la novela sexta firme las epístolas dirigidas a Hillo como Telémaco, en una abierta mueca humorística que no deja de apuntar a un modelo literario, considerado por García Castañeda (2012: 46) fundamental en esta serie. También en estas novelas explora Galdós la variación que implica un cambio en el emisor, motivado por el destinatario. En este caso encontramos situaciones vinculadas por el motivo del engaño, de manera que según se escriba a un personaje u otro los hechos aparecen con distinto perfil. Recuérdese, en De Oñate a La Granja, las cartas tan distintas que escribe Pilar a Fernando e Hillo, encerrados, o en Los Ayacuchos la correspondencia preparada por Demetria para engañar a Ibero que, a diferencia de aquella novela, solo es referida.

Por otro lado, encontramos también la variante de la carta dependiente no de uno sino de dos emisores. En Los Ayacuchos, donde tan importante es la técnica epistolar, Fernando y su madre se dirigen a Demetria "con una sola voz y te escribimos con una sola pluma" (2016b: 781), mientras que Valbanera confiesa a su amiga Pilar que su carta ha sido revisada y pulida por su marido. La justificación de ello viene nuevamente ligada a la singular oscilación del género entre los ámbitos público y privado, pues como confiesa: "Dice mi marido que debe ir el documento muy bien apañadito, porque su indudable importancia lo destina ciertamente a la conservación" (2016b: 701) ${ }^{9}$. También en Vergara una carta que Hillo había iniciado es concluida por Fernando (Cap. II) y en Los Ayacuchos una de Gracia es interrumpida por la escritura de Demetria (Cap. XIV). El tradicional dispositivo, por tanto, de la carta dentro de la carta no es inusual en este conjunto novelesco, por lo que el incremento de puntos de vista sobre la realidad vivida por los personajes se ve intensificado.

En lo que concierne, por otra parte, a la búsqueda por conseguir un registro personal en el discurso de cada personaje, Montesinos censuró a Galdós por considerar que las cartas "parecen de la misma mano" (1980: 100). Si comparada con otras novelas del autor esta serie puede no mostrar la conseguida polifonía tanto en las voces como en la escritura epistolar de los personajes, quizá pueda resultar excesiva tal crítica pues, sin duda, se aprecia en muchas ocasiones el deseo por mostrar el estilo personal de los personajes en sus cartas. Cabría recordar, así, la singular traslación que se produce del estilo de Hillo, apoyado en su jerga taurina, a la escritura epistolar de la mano oculta (De Oñate a La Granja, Cap. V). En general, y dado el relieve de la escritura epistolar de tal personaje, se aprecia el deseo por la consecución de un personal estilo definidor del mismo, objeto, como se comentó, de las interpretaciones de sus destinatarios que buscan descifrar el enigma a través de él. También se advierte la búsqueda de la caracterización epistolográfica de Gracia de quien se reproducen unas cartas llenas de faltas ortográficas (La estafeta, Cap. XVIII. Cap. XXIII), que ella misma limará en su posterior carteo, como indicio explícito de su proceso de madurez.

Asimismo, resulta habitual en la correspondencia epistolar de tan elevado número de emisores que estos reproduzcan las voces de los otros. Jost (1968: 105) consideró que

9 Precisamente de la consulta del archivo epistolar de su padre extraerá Juana Teresa la información de quién es el padre de Fernando. 
la integración de diálogos en la novela epistolar rebajaba el grado de verosimilitud, al aparecer dotado el narrador de una memoria admirable que le permite reproducir las palabras de otros. Sin duda tal crítica - extensiva al dominio de este género-alcanza en muchos momentos a la obra galdosiana, en la cual llegamos a encontrar, incluso, cartas bajo formato teatral.

Si en el polo de la emisión se advierten notables variaciones, similar amplitud cabe percibir en el de la recepción. En La estafeta encontramos una de las situaciones más llamativas, al reproducirse en el Cap. XVII una carta de Navarridas a Fernando en la que se incluyen dos esquelas de Demetria y Gracia, dirigida la primera a Valbanera. Si aquí cabe hablar de un destinatario interpuesto previsto, el uso que de estas hace Valbanera da pie a la situación de destinatario intruso no autorizado, frecuente en estas novelas. Ella las envía, así, a Pilar quien le manifiesta sus dudas acerca de la interpretación de ambas. Si en la novela epistolar el lector, como destinatario intruso de toda la correspondencia, ostenta una posición privilegiada al acceder a todas las cartas, el de esta novela goza plenamente de tales condiciones pues, a la información procedente de esta obra, unirá la necesaria lectura de las anteriores en donde, de la mano del narrador omnisciente, asistió al encuentro de Fernando con las hermanas. Desde tal posición corregirá, sin duda, la desconcertada perspectiva de la madre del héroe.

En lo que respecta a la recepción, dos son los esquemas repetidos, ligados al destinatario añadido autorizado o no. Si existen abundantes ejemplos de la primera situación-Mendizábal, Cap. XXV; De Oñate a La Granja, Cap. XII-, también los hay de la segunda. La intrusión de receptores no previstos alcanza incluso al ámbito de la correspondencia amistosa -recuérdese la intrusión del marido de Valbanera en el carteo de ambas amigas- $\mathrm{o}$ amorosa-Gracia confiesa a Fernando que ha leído todas las cartas de ambos enamorados (Los Ayacuchos, Cap. XIII)-. También Galdós manejará el viejo artificio literario de la epístola memorizada, a través del cual se produce un desdoblamiento de destinatarios. Si en la tradición literaria dicha memorización solía venir justificada por un contexto amoroso ${ }^{10}$, en La campaña del Maestrazgo no es este el que rodea el relato de D. Beltrán cuando reproduce a la hija de su amigo Lucio la carta de aquel. Singular relieve de destinatario no previsto se halla en Luchana, donde Prudencia oculta la carta que Mendizábal dirige a su esposo y que se reproduce, resumida, a través del fluir interior de la tía de Aura.

$\mathrm{Si}$ en todos estos casos las cartas, tanto reproducidas como referidas, son dadas a conocer al lector, incorporándose en la trama, también Galdós manejará el artificio epistolar para originar huecos en la misma. Este sería el caso de la carta enterrada que una enigmática mujer debía entregar a Fernando, en La estafeta, o de esa carta quemada por Rafaela para impedir que Ibero identifique a su amante, en Montes de Oca.

Contemplado este conjunto novelesco desde las variantes vinculadas a esos dos polos necesarios en la comunicación epistolar, parece claro que la serie galdosiana se

10 Recuérdese, por ejemplo, su manejo en la narrativa cervantina, con la humorística inflexión, al respecto, en el episodio de la embajada de Sancho al Toboso. 
distancia del esquema, tan vinculado a la novela epistolar, de una correspondencia íntima que refleja las emociones y sentimientos de los personajes que los manifiestan, en su secreta confidencialidad, al tú elegido. Lejos de ello, la abierta polifonía de las novelas galdosianas intensifica la variedad perspectivista al quebrantar ese rasgo, intrínseco al género epistolar, de una voz única que se dirige a otra, también específica. Aquí, junto a los casos de escritura y lectura únicas los hay, y son abundantes, de escritura y lectura mezcladas e interpuestas. El manejo, en consecuencia, de la técnica epistolar contribuye a intensificar el complejo mosaico abordado, de una tupida red de complejas relaciones interpersonales, en la que los personajes acuden, casi de forma compulsiva, a la escritura y lectura de cartas. Es tan amplio el abanico desplegado a tal respecto por el novelista, que los personajes cambian, continuamente, de función al aparecer como actores, narradores o receptores de unos hechos en los que todos están implicados.

\section{La coordenada espacio-temporal}

Como bien señaló Violi (1999), uno de los elementos que caracterizan a la carta como género es la presencia de la localización espacio-temporal como punto de referencia y lugar de la situación de la enunciación. En una carta siempre se nos ofrece el anclaje espacio-temporal que, una vez determinado, se desarrolla de forma interna a través de un mecanismo deíctico; de manera que si las referencias al "aquí" y "ahora" de la situación de la enunciación no son exclusivas del género epistolar, sí son rasgos específicos del mismo.

Será en las novelas con formato epistolar -total o parcial- donde se detalle tal coordenada, pues lo habitual en las cartas insertas es su ausencia. Dicho vacío se justifica plenamente en la correspondencia entre Fernando y su misterioso benefactor quien oculta también la fecha y lugar desde donde escribe. La proximidad espacio-temporal pronto, sin embargo, resulta innegable, por lo que en esta ocasión la comunicación epistolar no se ajusta a los parámetros canónicos de un diálogo en la distancia. Como Violi señaló (1987), si la carta presupone estructuralmente una distancia, puede utilizarse también para producirla cuando no la hay. En el presente caso son los obstáculos que dificultan la relación entre ambos personajes los que motivan que ella tenga que acudir a ese diálogo distanciado. Si también los obstáculos en su relación amorosa justifican que Fernando y Aura acudan a las cartas, distinta es la situación que se crea en torno a Pilar y su marido, cuando este descubre su secreto. Compartiendo el mismo espacio, la revelación que trastorna completamente a Felipe crea entre él y su mujer una distancia infranqueable ${ }^{11}$.

En general, no obstante, el carteo entre los personajes viene motivado por la distancia espacial, de manera que es a través de las epístolas de estos como se van presentando tanto los sucesos históricos como los propios de la ficción novelesca. En ambos casos el relato aparece siempre anexo a una focalización subjetiva que suele

11 Significativo resulta lo que cuenta Pilar a su amiga, cuando le comunica que le han dicho "que escribe cartas larguísimas y las rompe" (La estafeta, 2016b: 166). 
presentarse, además, especialmente comprometida o afectada por estos. Ello se debe, en gran medida, a la proximidad temporal que suele darse entre el tiempo del relato y el de la escritura pues, frente al modelo de la memoria, la carta suele caracterizarse por la relación de hechos cercanos. Como indicó Violi, en las cartas tienden a superponerse las referencias al tiempo de la narración y al de la escritura que, en ocasiones, manifiestan una mínima distancia. De ahí que se produzca, de forma bastante reiterada, la fusión entre la narración del suceso vivido y el acto de la escritura "en una especie de relato «en directo»" (1987: 93).

Si ya Richardson elogió como uno de los grandes méritos de la técnica epistolar su efecto de inmediatez, el mismo se aprecia de manera recurrente en estas novelas. Especialmente visible resulta en algunas cartas fragmentadas, a modo casi de cartadiario. Las amistosas entre Pilar y Valbanera presentan, en algún momento, tal disposición (La estafeta, Caps. XXVI y XXX) que, salvadas las distancias, podría evocar la conformación narrativa de la dieciochesca La Leandra de Valladares de Sotomayor. Quizá uno de los episodios en que tal esquema alcance mayor relevancia sea el del relato, detallado paso a paso, de Pilar a Valbanera, de su angustiosa situación por su conflicto matrimonial. También Fernando enviará alguna a su madre incorporando los sucesos vividos en esos días (Vergara, Cap. VI) o a Demetria, acerca de los altercados en Barcelona que vive muy de cerca (Los Ayacuchos, Cap. XXV). En esta novela, los desplazamientos de Fernando dan lugar a una abundante correspondencia de este con su madre y Demetria en la que es común el manejo del mencionado esquema cartadiario. Resulta, en tal sentido, significativo que sean las cartas de este y no las de sus corresponsales, las reproducidas, pues es a través de ellas como avanza la trama novelesca ${ }^{12}$. Como en el caso de la correspondencia amorosa mencionada, la selección de las cartas reproducidas revela a un escritor cuidadoso en la elección y ordenación de estos textos, que sabe bien cuáles debe reproducir o eludir.

Por lo demás, y ello resulta también rasgo propio del género, no es inusual que en la carta aparezcan referencias directas a la situación de la enunciación que condiciona la escritura epistolar. En algunas cartas encontramos, así, el motivo de la forzada interrupción por causas ligadas a la situación de quien escribe. En una de Pilar a Valbanera tiene que acabar precipitadamente, por la llegada del marido -"Ya viene, siento el coche. Adiós, mi amadísima" (La estafeta, 2016b: 133)-.También Hillo, vivamente impresionado por el ajusticiamiento de los soldados implicados en el asesinato de Ceballos, tiene que dejar de escribir -"Mi temblor y mi debilidad exigen que me recoja" (Vergara, 2016b: 219)-, y son las incontrolables emociones de Gracia las que interrumpen la carta que escribe a Fernando (Los Ayacuchos, Cap. XIII).

Por otra parte, como indica Todorov (1971: 32), no solo la situación de la enunciación sino también el aspecto del enunciado puede influir en el significado global de la epístola. La misma materialidad de la carta puede repercutir en su contenido. Si Todorov menciona rasgos como el papel o la tinta, cabría hablar de la propia escritura

12 En las mismas volvemos a apreciar ese efecto de inmediatez, consecuencia de la técnica epistolar: "Que me caigo de sueño...que no puedo más...” (Los Ayacuchos, 2016b: 812). 
como rasgo portador de significado. Un caso bastante claro lo hallamos en De Oñate a La Granja. Hillo, tras mucho tiempo sin noticias de la mano oculta, recibe una carta cuya letra reconoce si bien la percibe "un poco insegura" (2016a: 580). Tal signo preludia, aquí, el contenido epistolar pues el personaje escribe en un estado deplorable, tras haber estado próximo a la muerte. Singular resulta también el manejo de uno de los topos más habituales en la novela epistolar, vinculada a una correspondencia amorosa. Se trata de la suplantación metonímica de la amada por su carta que da lugar a que esta sea besada por su enamorado. Dicha convención aparece en algún momento en Los Ayacuchos, solo que sometida a una innegable reelaboración. Quien escribe a Fernando aquí no es la amada sino su hermana quien, tras haber dejado que Demetria lea lo escrito -en un nuevo caso de ampliación de destinatario-, provoca que esta la bese con intensa emoción, marcando con una cruz ese lugar. De nuevo, pues, volvemos a encontrar una llamativa quiebra en la tradicional confidencialidad de una correspondencia amorosa, pues la carta besada no es la escrita por la enamorada sino por un personaje ajeno, copartícipe e íntimamente involucrado, no obstante, en esa relación entre dos.

Asimismo, cabe señalar también que el uso del modelo epistolar polifónico plasma de forma notoria la simultaneidad de acciones en el tiempo. Respecto a ello, de nuevo será el anclaje espacio-temporal la guía que oriente al lector acerca de la construcción de la trama novelesca, sabiamente planificada, por otro lado, por los designios de un autor cuya implícita presencia acompaña siempre a la novela epistolar.

Si en su primera serie Galdós manejó, pues, al narrador personal único, conforme al modelo autobiográfico, en la tercera se inclina también por el uso del narrador personal que entremezcla, no obstante, con el manejo de la voz narrativa fuera de la historia. La elección, sin embargo, en este caso del modelo epistolar imprime un sesgo bien diferenciado a esta serie. Ahora no solo el número de narradores se multiplica, frente a esa perspectiva única, sino que la elección del formato epistolar da lugar también a ese innegable efecto de inmediatez por el que se acentúan las emociones y afectos de unos personajes que escriben, no sobre lo que les sucedió hace tiempo, sino sobre lo que viven en su mismo presente. Ya se trate de hechos históricos o de aquellos que tienen que ver exclusivamente con la trama novelesca creada por Galdós, los personajes muestran siempre cómo estos les afectan y conmueven íntimamente, trasladando, en definitiva, al lector esa mencionada sensación de relato "en directo".

En definitiva, si el género epistolar gozó de su época de gran esplendor y vigencia en el siglo XVIII, no cabe duda de que grandes escritores posteriores como Galdós supieron aprovechar las posibilidades intrínsecas del mismo y desarrollarlas conforme a una moderna conformación del discurso novelesco.

\section{BIBLIOGRAFÍA}

BAQUERO ESCUDERO, Ana L. (2003): La voz femenina en la narrativa epistolar, Universidad de Cádiz.

BEHIELS, Lieve (2001): "Las cartas de Pilar de Loaysa: ejercicio de poder y exploración de la conciencia", Anales Galdosianos, 36: 65-72. 
BERNAL SALGADO, José Luis (1985): "La forma epistolar y sus funciones en $L a$ estafeta romántica de Galdós”, Anuario de Estudios Filológicos, VIII: 19-40.

CALAS, Frédéric (1996): Le roman épistolaire, Paris: Éditions Nathan.

CANTOS CASENAVE, Marieta (2015): "Cartas y epìstolarios. Cultura de la correspondencia misiva y práctica editorial”. Cuadernos de Ilustración y Romanticismo, 21, 1-5.

DÍEZ DE REVENGA, F. Javier; DÍEZ DE REVENGA, Ma . Josefa (1989): "Realidad y literatura en los Episodios Nacionales: La Estafeta Romática" III Congreso Internacional de Estudios Galdosianos. Las Palmas de Gran Canaria: Cabildo Insular de Gran Canaria, II, 303-312.

GARCÍA CASTAÑEDA, Salvador (2012): "La tercera serie", La historia de España en Galdós, D. Troncoso, S. García Castañeda, C. Luna. Universidade de Vigo, 41-57.

GUADALUPE MELLA, Olga (2016): La correspondencia privada y literaria de Juan Valera, Emilia Pardo Bazán y Benito Pérez Galdós, Universidad de Santiago de Compostela.

GUILLÉN, Claudio (1998): "La escritura feliz: literatura y epistolaridad", Múltiples moradas, Barcelona: Tusquets, 177-233.

JOST, François (1968): "L'évolution d'un genre: le roman épistolaire dans les lettres occidentales", Essais de littérature comparée, Fribourg: Éditions Universitaires, 89-179.

MONTESINOS, José F. (1980): Galdós III, Madrid: Castalia.

MONTESQUIEU, Charles Louis de Secondat (1997): Cartas persas, Trad. F.J. Hernández. Madrid, Cátedra.

OVIDIO (1989): Arte de amar. Trad. C. López, Madrid, Gredos.

PAGÉS-RANGEL, Roxana (1997): Del dominio público: itinerarios de la carta privada, Amsterdam: Rodopi.

PARADISSIS, Aristides G. (1978): "Una influencia balzaquiana en los Episodios $\mathrm{Na}$ cionales de Benito Pérez Galdós", Thesaurus, 33, 3: 446-461.

PENAS, Ermitas (2013): La tercera serie de los "Episodios nacionales" de Benito Pérez Galdós: Quijotismo y Romanticismo, Vigo: Academia del Hispanismo.

PÉREZ GALDÓS, Benito (2016a): Episodios nacionales. Tercera serie I. Zumalacárregui. Mendizábal. De Oñate a La Granja. Luchana. La campaña del Maestrazgo. E. Penas (ed.), Madrid: Biblioteca Castro.

(2016b): Episodios nacionales. Tercera serie II. La estafeta romántica. Vergara. Montes de Oca. Los Ayacuchos. Bodas reales. E. Penas (ed.), Madrid: Biblioteca Castro.

RUEDA, Ana (2001): Cartas sin lacrar, Vervuert: Iberoamericana.

SOTELO, Marisa (2015): "La carta apócrifa de Miguel de los Santos Álvarez en La Estafeta Romántica de Pérez Galdós", Frutos de tu siembra, Santander: Sociedad Menéndez Pelayo, 263-275.

TODOROV, Tzvetan (1971): Literatura y significación, Barcelona: Planeta. 
TONYÈ, Alphonse (2008): Sémiostylistique. Approches du roman épistolaire, Bern, Peter Lang.

UREY, Diane F. (1985): "The Confusion and the Fusion of History and Fiction in the Third Series of Galdós Episodios Nacionales", Philological Quarterly, 64: 459-473.

VIOLI, Patricia (1987): "La intimidad de la ausencia: formas de la estructura epistolar", Revista de Occidente, 68: 87-99.

(1999): "Cartas", Discurso y Literatura, T. A. Van Dijk (ed.), Madrid: Visor, 181-203.

\section{PERFIL ACADÉMICO Y PROFESIONAL}

Ana Luisa Baquero Escudero es Catedrática de Literatura Española. Dpto. Literatura Española, Teoría de la Literatura y Literatura Comparada. Facultad de Letras. Universidad de Murcia.

Su línea de investigación se ha centrado en el ámbito de la narrativa española, con una incidencia especial en la obra de Cervantes y de los escritores decimonónicos.

Fecha de recepción: 04/03/2020

Fecha de aceptación: 19/04/2020 